\title{
Correction: Influence of CYP3A polymorphisms on tacrolimus pharmacokinetics in kidney transplant recipients
}

Ibtissem Hannachi - Zohra Chadli - Emna Kerkeni - Abdessalem Kolsi - Mouna Hammouda • Amel Chaabane · Nadia Ben Fredj • Yvan Touitou • Naceur A. Boughattas - Karim Aouam

Published online: 9 September 2020

(c) The Author(s), under exclusive licence to Springer Nature Limited 2020

Correction to: The Pharmacogenomics Journal

https://doi.org/10.1038/s41397-020-00179-4

The original version of this Article omitted the word "of" in the title and should have read "Influence of CYP3A polymorphisms on tacrolimus pharmacokinetics in kidney transplant recipients". This has now been corrected in both the PDF and HTML versions of the Article. 